\title{
POLÍTICAS CURRICULARES Y DE EVALUACIÓN EN MÉXICO, PROYECTOS DE LOS ORGANISMOS INTERNACIONALES Y CAMBIOS EN LA PRÁCTICA DOCENTE
}

\author{
Ángel Díaz-Barriga \\ Instituto de Investigaciones sobre la Universidad y la Educación - IISUE-UNAM, México
}

\begin{abstract}
Resumo
Este ensaio analisa a forma como as políticas curriculares e a avaliação educacional durante o período do neoliberalismo no México tiveram impacto na prática docente. Inicia apresentando a forma como, a partir da crise econômica dos anos oitenta, dois elementos convergiram no país: o acesso de um grupo neoliberal ao país e o ativismo de Organismos Internacionais que afetaram as questões educacionais. Uma confluência que durou quase quarenta anos, com sua presença e reflexo nas políticas educacionais (curriculares e de avaliação) aumentando com o passar do tempo. Esclarece-se que o discurso destas organizações não é suficiente, mas para a sua implementação é necessário que as autoridades educativas e os técnicos as assumam e as levem adiante. Em todos esses anos foram feitas mudanças no sistema educacional, outras perspectivas foram estabelecidas para nortear o trabalho docente, na prática pedagógica algumas mudanças foram observadas, nem todas as desejadas, nem todas que saíram como se esperava. A ideia de qualidade, avaliação, estímulo económico, comparação entre os resultados dos alunos foram o que norteou o trabalho realizado durante todos esses anos. Nas seções que compõem este trabalho, buscamos dar conta de como foram progressivamente realizadas, ao mesmo tempo em que se reconhece que há um núcleo forte na tradição docente, que transita horizontalmente nas escolas e no mesmo sistema de formação inicial de professores, que faz parte do DNA da prática em sala de aula. Por fim, o trabalho termina por identificar o acesso de um novo grupo ao poder, de cunho nacionalista e com signos de esquerda, que rompe com algumas propostas estabelecidas no campo político, mas no campo educacional não tem logrado, pelo menos até agora, construir um projeto educacional completamente diferente do estabelecido.
\end{abstract}

Palavras-chave: Neoliberalismo; México; Políticas curriculares.

\section{Resumen}

En este ensayo se analiza la forma como las políticas curriculares y de evaluación educativa durante el periodo del neoliberalismo en México han tenido un impacto en la práctica docente. Se parte de presentar la forma como a partir de la crisis económica de los años ochenta, confluyeron dos elementos en el país el acceso de un grupo de corte neoliberal al país y el activismo de los Organismos Internacionales que incidió sobre temas educativos. Una confluencia que duró casi cuarenta años, aunque su presencia y reflejo en las políticas educativas (curriculares y de evaluación) se fue incrementando conforme avanzó el tiempo. Se aclara que no basta con el discurso de estas organizaciones, sino para su implantación se requiere de autoridades y técnicos educativos que las asuman y las lleven adelante. En todos estos años se realizaron cambios en el sistema educativo, se establecieron otras perspectivas para orientar el trabajo docente, en la práctica pedagógica se observaron algunos cambios, no todos los deseados, no todos por los que se apostó. La idea de calidad, evaluación, estímulo económico, comparación entre los resultados de los estudiantes van a ser el signo que oriente el trabajo realizado durante todos esos años. En los apartados que conforman este trabajo se busca dar cuenta de cómo se fueron realizando progresivamente los mismos, al mismo tiempo que se reconoce que existe un núcleo fuerte en la tradición docente, el que transita de manera horizontal en las escuelas y en el mismo sistema de formación inicial de docentes, que forma parte del ADN de la práctica en el aula. Finalmente, el trabajo termina identificando el acceso de un nuevo grupo al poder, de corte nacionalista y con signos de izquierda, que rompe con algunas propuestas establecidas en el campo político, pero en el ámbito educativo no logra, por lo menos hasta este momento, construir un proyecto educativo completamente diferente al establecido.

Palabras-clave: Neoliberalismo; México; Políticas curriculares.

ISSN 1645-1384 (online) www.curriculosemfronteiras.org

http:/ /dx.doi.org/10.35786/1645-1384.v21.n3.2 


\section{Revolución cubana, movimiento del 68 y la incorporación del pensamiento pedagógico eficientista en México}

La incorporación de una visión educativa centrada en la eficacia tiene sus raíces previas al surgimiento global del neoliberalismo desde los años sesenta y setenta del siglo XX. Forma parte de una lucha de prevención ideológica contra las ideas que cambio social que se abrieron a fines de la década de los años cincuenta con la revolución cubana. La respuesta de Whashington, ante la ideología de esta revolución fue el establecimiento de la llamada Alianza para el Progreso (Hodara, 2014) por la cual el gobierno estadounidense establecía un marco de diez años para una amplia cooperación e inversión para América Latina con el fin de que superara sus dificultades. Un pretendido marco de protección ideológica contra las ideas del comunismo que flotaban en el aire y de la guerra fría que campeaba en ese momento.

Aunado a esta situación México experimentaba una profunda crisis política en la que el movimiento estudiantil de 1968 fue reprimido brutalmente por el ejército en 1968. Una de las demandas de ese movimiento era una apertura política. Misma que a cuentas gotas se empezaría a abrir en los últimos treinta años de ese siglo. Sin necesariamente lograrla por completo.

Es importante tener en cuenta este contexto internacional y nacional para comprender el inicio de una política educativa que buscó transformar la mentalidad de los docentes. Estos debían dejar de concentrarse en la enseñanza como responsabilidad primordial, para transitar hacia una docencia centrada en la calidad, eficacia y resultados de la educación. Cambiar la concepción que los docentes tienen de su trabajo sería una tarea de mediano plazo, cuyos logros no se verían en una generación, pero era importante iniciar con ella. ${ }^{1}$

Es necesario considerar este complejo contexto para comprender una primera fase de la modernización educativa realizada en los años setenta del siglo XX en las reformas educativas de los años setenta del siglo XX. Aunado a la Alianza para el progreso se empezó a divulgar e incorporar en la región con muy diversas estrategias un conjunto de teorías educativas formadas a lo largo del siglo XX en la Unión Américana. De esta manera se traducirían e imprimirían, con apoyo de diversas agencias estadounidenses la Agencia Internacional del Desarrollo (AID) y el Departamento de a Asuntos Educativos de los Estados Américanos (OEA) miles de ejemplares de distribución gratuita de los textos de Bloom (Más de 40 mil ejemplares), Tyler y Popham\&Baker. En la expresión de Carnoy se trató de un acto de imperialismo cultural (Carnoy, 2000). De esta manera llegaba a formar parte de los insumos para las reformas educativas, la teoría curricular y de objetivos de aprendizaje y la planeación educativa.

La teoría de objetivos de aprendizaje, referente básico para la construcción de los nuevos planes de estudios de los años setenta del siglo pasado, partía de la descripción de los comportamientos conductuales que mostrarían los aprendizajes logrados. Concepto que en sus últimas expresiones se denominará "aprendizaje esperado" y a partir de la inclusión del enfoque de la educación por competencias se expresará en "evidencias de aprendizaje". 
En este contexto se buscó que los docentes transformarán su concepto sobre la docencia para transitar de una perspectiva centrada en pensar su tarea en función sólo de la enseñanza, esto es sobre como organizar su curso a través de la selección de contenidos, hacia una noción de aprendizajes referido como cambio conductual y, posteriormente logros de aprendizaje, aprendizajes esperados y evidencias de aprendizaje. El argumento sería pensar en lo que el alumno tiene que mostrar y no en la tarea del docente.

Los planes y programas de estudio estuvieron marcados por detalladas descripciones de comportamientos que mostrarían los aprendizajes logrados por los alumnos. Hubo ocasiones en donde los docentes tenían que firmar el número de objetivos del programa que trabajarían en cada sesión de clase. Las bases de lo que se acentuaría con el ingreso del neoliberalismo ya estaban asentadas en el país.

Pero como la experiencia ha mostrado el cambio en las concepciones que orientan el trabajo docente no se produce de un momento a otro. No podemos desconocer que desde la incorporación de estas teorías los docentes en México fueron incorporando los elementos discursivos que acompañaban al nuevo lenguaje, incluso que permitieron incorporar a su práctica educativa algunos elementos de estas propuestas pedagógicas, sin embargo, la idiosincrasia del docente en México se enfrenta a una visión de pedagogía humanista que forma el ADN de las escuelas normales, responsables de la formación inicial del docente.

\section{Crisis económica, programas de rescate e impulso a la calidad de la educación}

La crisis económica que vivió México a principios de los años ochenta del siglo pasado fue el contexto para que los organismos internacionales, en ese momento el FMI y el Banco Mundial activaran su activismo que fue muchos más allá del rescate económico. Con las llamadas políticas de ajuste estructural intervinieron el primero en el gasto gubernamental destinado a los sectores sociales, entre ellos a la educación, acentuando la divulgación de un discurso educativo de corte eficientista, incorporando de una manera mucho más abierta la teoría del capital humano. (Melendres, 2002).

El neoliberalismo que ya se había instalado desde 1983 como resultado de la crisis económica y la llegada al poder de un grupo que había realizado su formación de posgrado en los Estados Unidos. Junto con los programas de ajuste se asumió que los países en crisis económica tendrían que participar en el mercado global, asumiendo las reglas de intercambio del mismo.

México experimentará tres décadas en el impulso de abierto de políticas neoliberales. Si bien el grupo político que llegó al poder público inició en los años ochenta, lo que pudo realizar esa gestión básicamente fue lidiar con la crisis económica con el apoyo fundamental tanto del FMI como del Banco Mundial. Ya estabilizada la crisis vendrán treinta años la última década del siglo XX y las dos primeras del XXI, donde las políticas de corte neoliberal tendrán mayor impacto posible. 
Estas políticas posibilitaron que el discurso de los organismos internacionales tuviera un impacto sin precedente en la conformación de las políticas nacionales, en particular para nuestro caso en las políticas educativas. Como expresa Coraggio (Coraggio, 1995), no basta con la difusión del discurso de tales organizaciones si no encuentran en los políticos y técnicos de un país, la receptividad necesaria para traducir a políticas, a proyectos y a programas específicos lo que tal discurso plantea.

Fueron los políticos y técnicos especializados nacionales, no necesariamente especializados en educación, los que dieron cuerpo a tales intenciones trabajando fundamentalmente desde las tesis de la teoría económica del capital humano.

En este sentido es necesario comprender la complejidad que generaron los diversos proyectos de cambio en los distintos segmentos de la sociedad, en particular los referidos a la educación, en las políticas de corte neoliberal se mezcló la propuesta de participar en un mundo globalizado en detrimento de las visiones nacionalistas que habían privado hasta ese momento o desde la perspectiva desarrollista que impulsó la CEPAL para la región desde finales de la segunda guerra mundial, (CEPAL, 1992) con una serie de planteamientos económicos de quienes estaban cercanos a la escuela de Chicago, los llamados "Chicago Boys". Empezó a privar la propuesta de integrarse y ser reconocido como parte de los países de las economías más fuertes del mundo, como la aceptación para que México formara parte de la OCDE en 1994.

Estos cambios fueron en sentido contrario a una historia nacional y a la formación de un sistema educativo de corte nacionalista gestada por el movimiento de la Revolución Mexicana de los primeros años del siglo XX. Movimiento que permitió la conformación del sistema educativo mexicano en sus diferentes subsistemas preescolar, primaria, secundaria, media superior y superior, así como en la educación normal. Un sistema educativo de corte profundamente nacionalista, sostenido en la parte académica por múltiples generaciones de docentes que fueron adquiriendo esta identidad formativa desde sus primeros años de escolaridad y, que la formación inicial de docentes, reforzó permanentemente. De manera, que los cambios propuestos siempre enfrentaron una forma de ser y de concebir la educación del gremio docente que no ha sido fácil transformar y, que incluso en los últimos años va gestando proyectos de formación alternativa para sus regiones acordes a diversos procesos sociales que vive el mundo y el país.

El neoliberalismo se estaba impulsando a grandes pasos en la década de los noventa con transformaciones en múltiples órdenes privatizaciones, establecimiento de la primacía de la lógica del mercado, establecimiento de una generación de políticas educativas para impulsar la calidad de la educación.

Pero la década de los noventa es también la década de las grandes convulsiones en el país que al menos señalarían que esa transformación pretendida enfrentaría varios obstáculos. En particular el año de 1994 podría señalarse como en el que las contradicciones sociales llevaron a una serie de convulsiones sin precedente en el país. El primer día del año estuvo marcado por dos eventos de rango completamente diferente, desde el punto de vista económico la entrada en vigor del Tratado de Libre Comercio de América del Norte (NAFTA, por sus siglas en inglés), firmado entre los gobiernos de Canadá, Estados Unidos 
y México, mostraría la cara de quienes buscaban esa integración comercial con el primer mundo (Riquelme, 2018). El inicio de la operación del Tratado coincidió paradójicamente con el levantamiento en armas de un grupo indígena de Chiapas conocido como el movimiento zapatista. (Cedilo-Cedillo, 2012), este acto que en estricto sentido no representaba un problema de índole militar que la autoridad no pudiera reprimir en el fondo abría a los ojos del país y del mundo la existencia de un mundo indígena marginado, sería la expresión local y particular de la enorme marginación social que viven más de 56 grupos originarios en el país. Representaba el punto más claro de una contradicción que empezaría a dar sus frutos en el terreno social, cultural y educativo paulatinamente. El punto de la contradicción entre eliminación del nacionalismo e incorporación al mundo global empezaba a desmembrarse. Si bien este proceso duraría veinte años con mucha fuerza y en este momento expresa algunas episodios que indican que se realizaría un cambio de ruta. Aunque si vemos las experiencias de algunos países latinoamericanos que han pasado por estos cambios, no hay garantía que este conflicto entre mundo globalizado y atención a los problemas nacionales se resuelva de una manera definitiva.

Pero otros dos eventos marcarían el año de 1994 como uno de los más compulsos que haya vivido el país en la historia moderna, por una parte los relevantes asesinatos políticos que se dieron durante el año por el que perdieron la vida el candidato oficial a la presidencia de la república, seguido un poco más adelante por el asesinado del líder del PRI, partido oficial, lo que significó un quebranto significativo para el grupo en el poder, el que sin embargo lograría que el proyecto neoliberal siguiera avanzando. Finalmente, en diciembre de ese año, estalla una de las devaluaciones más fuertes que haya tenido la moneda mexicana, ocasionando una convulsión no sólo en la economía nacional, sino con un impacto significativo internacional, la llamada "Crisis del Tequila" que obligó al gobierno de los EEUU a presionar a la reserva federal para que estableciera un urgente programa de rescate de la moneda mexicana.

Esta crisis fue desgastando al Partido Institucional Revolucionario (PRI) que había gobernado ininterrumpidamente al país durante 70 años, atravesado siempre por diversas ideologías, pero obligado por sus propios errores, agravios a la población, despilfarro de recursos públicos y un hartazgo social, llevaron a que perdiera la presidencia de la república en el año 2000. Ingresó al poder por primera vez el Partido Acción Nacional (PAN) un partido que también estaba en proceso de desfiguración de su ideología inicial, mucho más cercana a la doctrina social de la iglesia católica. El primer presidente de la república de procedencia panista, fue un empresario que definió su gobierno, como un gobierno de empresarios para empresarios. Los doce años de gobiernos del PAN, permitieron que los proyectos neoliberales siguieran avanzando en la parte de la economía, incrementaron la corrupción que había en el manejo de los recursos públicos, pero en la política educativa abrieron ya de una manera amplia la participación de la OCDE en la toma de decisiones para el establecimiento de políticas educativas. Tema que finalmente se acentuó con el retorno del PRI al gobierno de la república en 2012 y las reformas constitucionales en materia educativa, así como en las leyes secundarias, que ya descaradamente estaban totalmente alineadas a las recomendaciones que la OCDE establecía para el sistema educativo. 
Estos temas no guardan una relación directa con la conformación de las políticas educativas de corte neoliberal, las cuáles se siguieron desarrollando de manera paulatina, pero sí reflejan el contexto nacional que finalmente dificultará el éxito pleno de lo que se pretendía

\section{Las diversas formas en que ese modelo educativo se fue materializando: Constructivismo, Competencias, Aprendizajes Clave, Innovación}

Los últimos treinta años, a partir de la década de los años noventa del siglo pasado se podrían considerar como en la que se inicia la amplia difusión de un discurso de los Organismos Internacionales construido con categorías y conceptos radicalmente diferentes a los que existían en el sistema educativo. Calidad/Evaluación/Financiamiento serán los ejes de este nuevo discurso educativo inspirado en las tesis de la Economía de la Educación.

Los planteamientos pedagógico-didácticos que se venían trabajando en el debate educativo nacional, así como la perspectiva de una formación humanista y nacionalista de los educandos se hicieron de lado para dar pauta a la formación del capital humano. Tema ciertamente discursivo, este último, pues este concepto nunca figuró en el lenguaje de los docentes, ni en su concepción del trabajo

El activismo de los Organismos Internacionales Banco Mundial se expresó a principios de los años noventa con la publicación y facilitación del acceso $^{2}$ de un conjunto de documentos en los que se establecía las deficiencias e ineficiencias que tenía el sistema educativo, sostenían que no era un problema sólo de incrementar recursos. Incluso el Banco Mundial establecía la tesis de que el incremento de recursos económicos al sistema educativo ya había mostrado que no necesariamente iba acompañado por una mejora en su funcionamiento, era necesario por lo tanto impulsar una reforma mucho más amplia, de esta manera publicaría La educación primaria un documento de política (BancoMundia, 1992). Por su parte, la CEPAL replantearía sus planteamientos que impulsaron una política desarrollista en América Latina entre 1950 y 1980, hacia una visión claramente articulada al neoliberalismo, asociándose con la oficina de la UNESCO de Santiago de Chile publicarían el documento Educación y conocimiento. Eje de la transformación productiva con equidad (CEPAL, 1992). Ambos textos representan la propuesta de establecer políticas para la educación de un corte diferente. Calidad y evaluación empezaron a ser los ejes de las mismas, mientras que financiamiento se constituyó en la llave para el logro de las mismas. La relevancia de estos dos documentos se debe tanto a la conformación de un discurso eficientista relacionado con la educación, como al impacto nacional que tuvieron en los tomadores de decisiones.

Estos documentos fueron objeto de análisis en primer término de los responsables de la conformación de la política educativa, aunados al trabajo que realizaron en su momento un conjunto de académicos que se sumaron tanto a la crítica de lo que acontecía con la educación, dando un apoyo incondicional a la elaboración de nuevos proyectos educativos. 
A esta dinámica generada por los Organismos Internacionales se asoció la creación de un grupo de intelectuales, en principio plural y de diversa índole, pero que en la parte educativa asumieron los cuestionamientos que el nuevo discurso neoliberal estaba conformando hacia la educación. El sistema educativo experimentaba una gran crisis, para mostrarla armaron un dramático diagnóstico, cierto en varios de sus elementos, pero con una explicación insuficiente sobre sus causas ${ }^{3}$.

Un grupo de intelectuales, asociados al grupo Nexos (Nexos, 2018), publicó un estudio sobre la situación del sistema educativo nacional en donde se ponía en evidencia los pobres resultados que obtenía el sistema educativo mexicano, se trata de una recopilación de varias investigaciones de corte cuantitativo publicadas bajo el título La catástrofe silenciosa (Guevara, 1992), este trabajo basado en la aplicación de diversos exámenes a gran escala a estudiantes causó un gran impacto social.

El eje de la argumentación de los capítulos agrupados en este libro es que cada día en la escuela se realiza en cada salón de clase una pequeña catástrofe silenciosa, pero de la cuál nadie daba cuenta. Al mismo tiempo tejió una afirmación que perduró por muchos años "en la escuela los niños no aprenden lo que tienen que aprender, los maestros no enseñan lo que tienen que enseñar" (Guevara, 1992) .

La falta de resultados educativos, tema que había sido objeto de amplias discusiones en las reuniones regionales realizadas desde los años cincuenta del siglo pasado, donde se consideraba que América Latina no se podía industrializar debido a la falta de una mano de obra calificada (Hodara, 2014), permitieron que con la incorporación del neoliberalismo todo se conjuntara para cuestionar lo que acontecía en el sistema educativo. Con base a todos estos diagnósticos se empezaron a diseñar una serie de propuestas de política educativa las que se cobijaron bajo el manto de la calidad de la educación (Plá, 2019) la evaluación y la eficacia escolar.

Los nuevos proyectos de alguna forma potenciaron algunos programas y disciplinas de las ciencias de la educación estadounidenses que se habían difundido en el país paulatinamente durante el siglo XX. También se acentuó el uso de las pruebas a gran escala para determinar el rendimiento que los alumnos muestran en su travesía por el sistema educativo, instrumentos que se apoyan en la teoría de los test (llamada evaluación) que, si bien ya se había incorporado desde los años treinta en el país, su empleo se acentuaría en la última década del siglo. Tema que sobre todo en el siglo XXI influiría en algunos cambios en la práctica docente, no necesariamente los que se estaban impulsando.

La educación dejó de ser concebida como el instrumento social de formación de ciudadanos con la que se pretendía equilibrar algunas condiciones de la segmentación social, tema que ciertamente no se había logrado a lo largo de ese siglo, para ser considerara exclusivamente como una herramienta en la formación eficaz del capital humano.

Con la teoría esta teoría se buscaba formar un capital humano que contribuyera a mejorar la economía del país, por primera vez en la política educativa, el Programa de Modernización Nacional de Modernización Educativa (1990-1994, 1990), estableció la preparación para el trabajo como una de las metas de la educación primaria, de la que egresan alumnos de 11 y 12 años de edad. 
A partir de este Programa Nacional, que en el fondo es un programa de política educativa y al mismo tiempo de política curricular, se realizaron tres tipos de acciones: a) cambios en los proyectos curriculares para la educación básica; b) impulso al establecimiento de exámenes nacionales a gran escala y participación y difusión de los resultados obtenidos por los alumnos en de los exámenes internacionales a gran escala; y, c) modificaciones en el sistema de formación docente, al mismo tiempo que impulso hacia la evaluación del desempeño docente.

a) La política curricular en los años del neoliberalismo

En este contexto, bajo la bandera de una modernización educativa, la tercera modernización ${ }^{4}$ en la segunda mitad del siglo XX, se estableció una reforma curricular que desde su integración se puede considerar regresiva al establecer nuevamente una estructura por asignaturas. ${ }^{5}$ Puesto que desde los años sesenta del siglo XX, las diversas reformas para la educación básica habían establecido una estructura por áreas de conocimiento y, no por asignaturas. ${ }^{6}$ contradictoriamente en medio de un movimiento internacional por trabajar el conocimiento interdisciplinario.

Las políticas curriculares una vez establecidos la estructura curricular por asignaturas, transitaron por tres momentos diferentes: La asunción del constructivismo en la reforma de 1993, hacia el enfoque de competencias en la reforma 2006, que desembocó en el establecimiento de estándares de desempeño en 2011 y, posteriormente la reforma por aprendizajes clave a partir de 2018. Aparentemente conceptos muy distintos pero que tienen como eje conductor el tema de trabajar sobre los logros de aprendizaje. Cada reforma responde a un momento de ascenso de un grupo político al poder. Grupos que tienen pequeñas diferencias ideológicas, pero que preservan hasta sus últimas consecuencias las tesis neoliberales que orientan la economía y en concordancia asumieron un proyecto educativo que tendría que ir avanzando a la par, en su transformación

\section{El retorno a las asignaturas}

Un efecto que tuvo el libro y los artículos difundidos sobre la catástrofe del sistema educativo, fue atribuir parte de esas deficiencias a que un currículo por áreas no permitía que los alumnos desarrollaran los aprendizajes que requerían. El texto aludido mostraba que había serias deficiencias en el conocimiento de la historia nacional, mismo tema que ubicaban en las deficiencias que identificaron en lo que se denominó conocimiento de ciencias naturales. Obviamente las matemáticas han sido permanentemente un conocimiento de difícil dominio por parte de los estudiantes.

El retorno curricular a asignaturas impidió profundizar en lo que el proyecto de áreas de conocimiento intentaba impulsar: la integración del conocimiento. Ya Taba preveía que un reto en esta forma de trabajo era permanecer en grandes generalizaciones (Taba, 1974), pero en vez de analizar las causas de las mismas se tomó la decisión de regresar a asignaturas. Lo que redundó en que un estudiante de 5 y 6 de primaria tenga que cursar 8 asignaturas por año, en vez de 5 áreas de conocimiento. 
Frente a cada reforma curricular se establecen cursos para los docentes con el fin de que conozcan los fundamentos de la reforma y analicen como los pueden aplicar en el aula. La reforma constructivista se abocó a ofrecer cursos que explicarán los fundamentos de esta perspectiva psicológica de construcción del conocimiento, en claro abandono de las visiones didácticas. ${ }^{7}$ Además de los cursos, los docentes recibieron un material de apoyo, el fichero pedagógico, que permitía orientar el trabajo que realizaban en el aula. Probablemente este fichero haya sido el elemento más relevante de esta reforma, algunos maestros que vivieron ese período todavía lo conservan como un tesoro.

Es necesario tener en cuenta que los maestros lograron incorporar sólo algunos elementos de la perspectiva constructivista en su trabajo docente, más allá de la cantidad de cursos sobre constructivismo, y de la implantación de otras lógicas de aprendizaje de diversas disciplinas, se cuenta con alguna evidencia de que los docentes laboraron a partir básicamente de estrategias metodológicas que resultaban eficientes para su trabajo escolar. ${ }^{8}$

\section{De Constructivismo a Competencias}

La primera década del siglo XXI, en lo que se denominó gobierno del cambio o de la alternancia en el poder, abrió grandes expectativas en todos los ámbitos de la sociedad. En el plano económico se mantuvieron las políticas neoliberales, aunque en lo educativo se incrementó el sistema de becas para estudiantes de escasos recursos. Tema que el Banco Mundial venía proponiendo desde los años noventa y que en ese momento se abría para estudiantes algunos que cursaban el último trabajo de la enseñanza media superior y superior. De igual manera se estableció el programa de escuelas de calidad, (SecretariadeEducaciónPública, 2015) por el que se asignaba algunos recursos económicos a las que cumplían con determinados indicadores. Evaluación de la calidad de convirtió en mostrar indicadores de desempeño. El programa fue un programa fundamentalmente de gestión institucional

Por estas razones uno de los principales cambios que inicialmente se realizaron estaban relacionados con el uso y difusión de los resultados de los exámenes a gran escala nacionales e internacionales, mientras que en el ámbito de las políticas curriculares, se asumió desde mediados de los primeros años del siglo el establecimiento de proyectos curriculares con el enfoque de competencias. La construcción curricular por este enfoque no necesariamente hacia desaparecer la perspectiva constructivista, ya que se supuso que se añadiría la visión de las competencias. Esta articulación evidentemente no ocurrió, las nociones constructivistas poco a poco se fueron diluyendo, frente a los temas técnicos que emanan de las competencias, en particular el trabajar para lograr evidencias de aprendizaje, lo que se traduciría posteriormente en el término aprendizajes esperados, como referente para la construcción del plan de estudios. Este proceso fue gradual pero apuntaba a una integración que se descubrió mucho más tarde así en 2004 se generó el que correspondía a preescolar, en 2008 para los tres primeros años de la enseñanza media y en 2009 para la educación primaria. 
La construcción curricular desde una perspectiva de competencias, atendía tanto a algunos aspectos del debate internacional, como a un tema que la OCDE venía trabajando desde finales de los años noventa (Simone \& Hersh, 2006). Tuvo varios impactos en el trabajo docente, en particular la recuperación del trabajo en el aula por proyectos, si bien los planes de estudios seguían integrados por asignaturas, se invitó a los docentes a organizar proyectos en educación primaria que pudieran integrar saberes de varias materias. La planeación de la clase, la que presentan los docentes para que sea aprobada por el director de la escuela, se hizo más complicada, había que señalar la competencia general y la específica, la evidencia de aprendizaje, las competencias actitudinales que demandaban ese trabajo y la propuesta metodológica. La planeación de la clase aprobada no guardaba relación con el trabajo que los docentes realizan en el aula.

Por otra parte, la publicación de los resultados que obtenían los alumnos en dos pruebas nacionales, generó el efecto contrario, los docentes empezaron a incluir en su forma de trabajo ejercicios similares a los que establecen las pruebas a gran escala con la finalidad de mejorar el resultado que los alumnos obtienen en ella.

Los gobiernos emanados de un partido alterno, el del PAN duraron 12 años, casi al término de mismos, publicaron un Acuerdo Secretarial que establecía estándares de desempeño para cada etapa curricular y, al mismo tiempo articulaba los planes de estudios de preescolar, primaria y secundaria. Tema que en estricto sentido pareciera ser el resultado de una política curricular que existía clara desde 2004 cuando se iniciaron las reformas desde el enfoque de competencias, pero que nunca fue explícito. En el acuerdo 592, (Secretaría-deEducación-Pública, 2011) la autoridad educativa establecía 5 campos formativos para toda la educación básica (preescolar, primaria y secundaria), campos integrados por asignaturas, que conforme se iba avanzando en la trayectoria escolar permitían al campo formativo subdividiera en más materias, con lo que se obligaba al estudiante a tener más dispersión en sus estudios. Así, mientras entre primero y tercero de primaria el alumno cursa 7 materias, en los tres primeros años se enseñanza media cursan hasta 10 asignaturas.

De igual manera establecieron los estándares de desempeño, los que en estricto sentido nunca se aplicaron, dado que en 2012 el PRI recuperaría nuevamente la Presidencia de la República, asumiendo la tarea de realizar nuevas reformas, con un sello más radical.

De hecho, lo que se puede señalar hasta este momento de la exposición es la forma como cada grupo político asume que tiene la necesidad de establecer una política educativa particular, no necesariamente radicalmente distinta. Lo que resulta importante destacar en este conjunto de cambios es la permanencia de la noción de eficiencia, calidad y evaluación, tema central que subyace en cualquier proyecto educativo. La mano de la OCDE cada vez será más clara, sin olvidar lo que establece Coraggio (Coraggio, 1995) ya expuesto, dado que el discurso de este organismo fue adoptado por políticos y expertos nacionales que los tradujeron en proyectos y acciones.

El regreso del PRI al gobierno de la República en 2012, se va a caracterizar por llevar adelante los 8 puntos del Acuerdo de Cooperación México-OCDE para Mejorar la Calidad de la Educación de las Escuelas Mexicanas (OCDE, 2010) que en este caso no se centró en impulsar una reforma curricular, sino en enfatizar la importancia de la eficacia del trabajo 
docente, buscando una definición de enseñanza eficaz y al mismo tiempo establecer sistemas de evaluación; mientras que el otro grupo de acuerdos señalan la necesidad de evaluar el desempeño docente, tema que abordaremos más adelante.

La política curricular no podía aceptar en silencio el acuerdo de articulación de la educación básica y el establecimiento de estándares de desempeño. Finalmente percibió que la eficacia en el trabajo educativo no se lograría desde esta perspectiva, pero tuvo la necesidad de establecer un cambio curricular que en estricto sentido no significó un cambio radical.

De esta manera y prácticamente al concluir el mandato presidencial se publicó lo que se denominó Nuevo Modelo Educativo, (SEP, 2017) que buscaba articular toda la educación incluyendo la media superior. Lo que en estricto sentido no logró, pues ésta por diversas razones mantuvo la estructura e integración que tenía previamente. El Nuevo Modelo Educativo conservaría la idea de campos formativos, pero ahora desagregados en campos de formación académica, de formación personal y de desarrollo. En la formación personal dejaron el tema de las artes y música, pero añadieron el tema de lo socioemocional. Tema que efectivamente quedó como algo donde se conservó la articulación de la educación básica y de manera forzada se buscó integrar a ese esquema la media superior. Un ejemplo de ello es que la materia tutoría donde se buscaba primero dar un apoyo a los estudiantes en sus estudios, el Nuevo Modelo Educativo la transfirió a una asignatura que denominó socioemocional. La articulación se perdió dado que en los tres últimos años del bachillerato se conservaron las materias pre-existentes como ética, literatura entre otras. Lo socioemocional procedía de los planteamientos de la OCDE.

Por su parte, dejó confusa la inclusión del enfoque de competencias, en general preferiría hablar de Aprendizajes Clave, aunque en las explicaciones del texto, se reconocería que la concepción subyacente fundamental es la de competencias. Aprendizajes Clave y competencias fueron un debate entremezclado en toda la década de los noventa en Europa, la misma OCDE en su documento de 1999 emplea ambos de manera indistinta. Lo básico es que mantuvo el tema de logros de aprendizaje e impulsó la idea de que no era necesario establecer contenidos en los programas de las materias, pues teniendo claros los logros se podría realizar la planeación didáctica.

Mientras que en el campo formativo de desarrollo establecía un espacio de autonomía curricular, un intento de flexibilizar los planes de estudios que durante todo el siglo XX tienen un carácter nacional. En este espacio curricular se daba autonomía a las escuelas sobre todo de los tres primeros años enseñanza media superior para incorporar una asignatura que considerasen fuese de importancia para los alumnos.

Se sugería materias donde los alumnos tuviesen dificultades de aprendizaje, espacios para uso de tecnologías digitales o práctica de deportes. En varias escuelas la autonomía curricular se convirtió en espacios de clubes para realizar deportes.

El Nuevo Modelo Educativo se construyó a partir de un proyecto muy ambicioso, abrió un espacio curricular para enseñanza del inglés desde preescolar hasta la conclusión de la enseñanza media superior, aspirando que al concluir este ciclo de formación los estudiantes se pudieran comunicar tanto en español, como en inglés. No tomó en cuenta las grandes desigualdades económicas que caracterizan al país, sobre todo para los proyectos de 
educación indígena se cuestionó esta meta, pues plantearon que ese grupo social tenía que dominar su lengua originaria (varias en situación de extinción y la mayoría con una característica de dialectos en su misma familia lingüística). La respuesta insensible de la autoridad educativa fue que concluyan el bachillerato pudiéndose comunicar en su lengua originaria, en español y en inglés. Esto es exigir más a los que menos condiciones tienen. De hecho, se hizo una amplia convocatoria para contratar profesores de inglés para las escuelas normales. A los docentes contratados se les dieron mejores condiciones laborales a los ya existentes. ${ }^{9}$

El Nuevo Modelo Educativo sólo se implantaría de manera parcial, dado que se empezó a aplicarse en agosto de 2018 en preescolar, primero y segundo de primaria y primero de secundaria. En noviembre se entregaría el gobierno a otro grupo en el poder, resultado por primera vez, de actores que sostenían la necesidad de regresar al nacionalismo en la educación.

El cambio didáctico que más se logró durante todos estos años fue el trabajo por proyectos por parte de los docentes, aunque también la distorsión de preparar a los alumnos a resolver preguntas cerradas como las que vienen en los exámenes a gran escala. El aspirado tema de lograr la homogeneidad en el aprendizaje de los alumnos y de trabajar en función de logros evidentes de aprendizaje no necesariamente se lograría.

b) La evaluación de estudiantes y de docentes

Evaluación es un tema asociado ampliamente a la calidad de la educación, al mismo tiempo que básicamente se confunde con medición, señalamiento de indicadores y clasificación de las personas. En el mundo educativo contemporáneo si no hay un número no se realizó la evaluación y, ese número se utiliza tanto para clasificar a los sujetos, como para hacer comparaciones entre unas personas e incluso entre diversas instituciones.

Evaluación ha sido un tema recurrente en las recomendaciones de los Organismos Internacionales, enfatizando tanto la evaluación (o sea) aplicación de exámenes a gran escala a los alumnos, como de lo que se empezó a denominar de desempeño docente.

\section{La generación de exámenes a gran escala para los alumnos}

A nivel internacional el establecimiento de pruebas a gran escala se origina en diversas organizaciones desde los años cincuenta del siglo pasado. En México la autoridad educativa estableció desde 1978 un área responsable de elaborar exámenes a gran escala. Una de los primeros exámenes que se empezó a aplicar el IDANIS (Instrumento Diagnóstico de Alumnos de Nuevo Ingreso a Secundaria). (Rodríguez-Cristerna \& Ruiz, 2021). Este instrumento que tenía como finalidad dar información a los padres de familia y profesores de secundaria sobre las condiciones con las que los alumnos ingresaban a la secundaria no logró realizar esta tarea. La información que se generó a partir del mismo se limitó a ofrecer un dato estadístico que difícilmente se lograba comprender a cabalidad. En una hoja donde estaban todos los alumnos inscritos se colocaba de manera vertical el resultado de varias mediciones, por ejemplo, habilidad matemática, habilidad de razonamiento, capacidad de 
comprensión lectora, entre otros. En la lista aparecían cerca de diez puntajes uno por cada columna (70.5, seguido de la media 68.9). Los padres de familia sólo tenían que firmar en esa lista que estaban enterados, esa firma era recolectada en el proceso de inscripción del alumno. Lo que ayudaba a que fuera firmada mecánicamente, además de la dificultad para lograr una comprensión real del significado que esa información tenía. De igual manera, esta información en estricto sentido no comunicaba nada a los docentes. Por otra parte, su utilidad real era para las autoridades educativas que por cada entidad federativa tenían una reunión para conocer la información que habían obtenido los estudiantes de ese estado.

Desde el año 2004, este examen se considera como un requisito para el ingreso a la escuela secundaria, pero en los hechos tampoco tuvo un papel relevante, aunque en algunos casos permitió determinar si el aspirante ingresaba al turno matutino o vespertino. No define el ingreso del estudiante a una secundaria pues cursarla es una obligación constitucional, más allá que la cobertura del nivel se acerque al $85 \%$ de la población en edad etaria y, por otra parte, nunca tuvo, ni ha tenido un impacto para el trabajo docente en el aula.

El gobierno mexicano desde los años ochenta había aceptado la participación de los alumnos en exámenes a gran escala internacionales, pero pedía confidencialidad en el manejo de los datos obtenidos. En 1995 los estudiantes resolvieron el examen de matemáticas y ciencias que ha elaborado por la IEA (TIMMS) y aplicado en 40 países. Los resultados de los alumnos mexicanos no fueron satisfactorios, razón por la cual el gobierno canceló su participación y solicitó a la asociación internacional que estos resultados no se incluyeran en el informe publicado. Lo mismo aconteció en 1997 con la participación de los estudiantes en la prueba elaborada por el Laboratorio Latinoamericano de Evaluación de la Calidad de la Educación de la UNESCO con sede en Chile.

Este tema fue objeto de diversos debates, fundamentalmente en los medios de comunicación donde se exigía al gobierno mexicano la publicación de esos resultados. Lo más relevante de esta situación es reconocer como la resolución de exámenes a gran escala nacionales e internacionales en la década de los noventa del siglo pasado, al mismo tiempo que su empleo respondía a las presiones que emanaban de los documentos de los Organismos Internacionales, por otra parte, no tenían impacto en el trabajo educativo.

Fue hasta el año 2002, ya con el primer gobierno de la alternancia política donde se aceptó participar en la prueba PISA que elaboró la OCDE y, por primera vez los resultados de estos exámenes son publicados y conocidos en el país. Obviamente los titulares de la prensa de esa época hicieron gran escándalo ante los bajos puntajes obtenidos en ellos. Los resultados fueron y siguen siendo deficientes, hay mucha literatura especializada que juzga si realmente tiene sentido participar en un examen construido en cuatro países y cuyo costo nacional es muy elevado, ante la falta de impacto en el trabajo docente. ${ }^{10}$

En ese año se crea por decreto presidencial el Instituto Nacional de Evaluación Educativa (INEE), institución que en los primeros veinte años del siglo XXI va a vivir situaciones muy complicadas que llevaron a su cancelación en el año 2019.

Los alumnos mexicanos no obtienen buenos resultados en los exámenes a gran escala, una respuesta de la autoridad educativa llevó a la acción de multiplicar la aplicación de exámenes a gran escala, bajo el supuesto de que si los alumnos resuelven más exámenes 
tendran que mejorar sus resultados. Tesis que contradice los planteamientos didácticos de que para mejorar el aprendizaje hay que mejorar el trabajo en el aula y no incrementar la aplicación de instrumentos de evaluación sin que los resultados retroalimenten a la práctica docente.

De esta manera entre el año 2003 y 2006, se crearon dos exámenes nacionales, uno fue elaborado por el Instituto Nacional de Evaluación Educativa creado en 2002, denominado Exámenes de la calidad del logro educativo (EXCALE), una prueba muestral para determinar los conocimientos que los alumnos de cuarto, quinto y sexto grado en las mismas áreas que evalúa PISA; mientras que en 2006 la autoridad educativa estableció el examen Evaluación Nacional del Logro Académico en los Centros Escolares (ENLACE) de carácter censal para ser aplicada en todas las escuelas.

Las autoridades educativas locales no se quisieron quedar atrás de la tesis examinadora, por lo cual procedieron a que sus equipos técnicos elaboraran un examen a gran escala local. Hubo ocasiones en que los alumnos de 6 de primaria presentaban durante el curso escolar al menos 4 exámenes diferentes. Los supervisores escolares declaraban que sus docentes se la pasaban preparando alumnos para los exámenes, en lugar de trabajar los contenidos del curso. (Díaz-Barriga, A avaliação na educação mexicana: Excesso de programas e ausência da dimensão pedagógica, 2009)

Se puede afirmar que la autoridad educativa no ha sabido manejar los resultados que obtienen los alumnos en estos exámenes. En sus primeros años el INEE creó un taller de evaluación, técnicas de construcción de exámenes, sistemas de calificación, para periodistas, con la idea de que estos comunicadores entendieran el significado de las mediciones, no el significado pedagógico, sino la forma como se realizaba una medición específica $\mathrm{y}$, fundamentalmente, que en el manejo de los resultados no atacaran a la institución. Lo paradojal es que después de quince años se percibió que en realidad quien tendría que entender el significado pedagógico de estos resultados era el maestro y, para ellos no se crearon talleres, sino sólo se elaboraron documentos informativos. Elaborar documentos para los docentes con el fin de que comprendieran el sentido de los mismos se realizó hasta mediados de la segunda década del siglo. Tema que también es indicativo de la forma como el sistema considera a los docentes. El INEE cuando podía argumentaba que su tarea no era trabajar con docentes, tampoco lo era crear talleres de evaluación para periodistas.

Por otra parte, no necesariamente los diversos exámenes, por lo menos los tres que permanecieron por más tiempo: PISA, EXCALE y ENLACE, tenían los mismos propósitos, ni necesariamente estaban construidos sobre los temas que contienen los planes de estudios. De suerte, que cada medición en realidad medía lo que sus diseñadores establecían ,siguiendo únicamente los criterios para la construcción y validación de un ítem y de un conjunto de ítems. Así las preguntas de los exámenes nacionales avanzaban por una ruta que no necesariamente reflejaban en la definición de contenidos de los planes de estudios de cada reforma curricular. Nunca existió, ni existe una articulación entre diseñadores curriculares y constructores de exámenes a gran escala. La lógica de las reformas con relación a los contenidos caminaba por una ruta, la lógica de la construcción de los exámenes a gran escala por la otra. 
México vivió una efervecencia de la psicometría durante esos años. Los expertos en medición pululaban por todas partes y, cuando no eran suficientes, se recurría a expertos de otros países. En algún sentido se puede afirmar que la teoría de la medición, en la que se basan los tests, se iba perfeccionando transitando de la teoría del test clásica, a la teoría de la respuesta al ítem; de la estadística descriptiva a la inferencial; e incluso incorporar el modelo Rash. Lo importante era la solidez del modelo estadístico, no necesariamente el impacto que pudiera tener en el trabajo docente.

El costo económico de tal cantidad de sistemas de exámenes en su proceso de elaboración, calibración, aplicación y procesamiento de resultados fue siempre elevado. Unos exámenes construidos desde la perspectiva de un logro homogéneo de resultados, en un país que tiene desigualdades sociales y económicas muy extremas. Al grado que un profesor de una escuela indígena de Chiapas, ante la dificultad que tenían sus alumnos para responder el examen les pidió que subrayaran las palabras que no entendían, entre las cuales estaban: vacaciones, pasaporte, Disneylandia. Con estos elementos solicitó y obtuvo que el Consejo Nacional para Prevenir la Discriminación (CONAPRED) declarara en 2011 que la prueba ENLACE era discriminatoria. Declaración por la que se logró que en los últimos años de la segunda década del siglo ya no se aplicará en las escuelas indígenas.

Sin embargo, desde el inicio de la década de los años noventa del siglo pasado las autoridades gubernamentales iniciaron un trabajo para vincular los resultados que los alumnos obtenían en estos exámenes a una compensación salarial (Programa Carrera Magisterial) que podrían obtener los maestros. El resultado del examen llegó a ser ponderado como el 50\% del puntaje del docente para participar en el programa de Carrera Magisterial.

Los docentes se ingeniaron entre otras cosas a adquirir cuadernillos de preguntas y respuestas cerradas para entrenar a los alumnos en la resolución de estos exámenes. La misma autoridad educativa comenzó también a pedir a los docentes, en donde se iba a aplicar la prueba PISA, que trabajaban con sus alumnos la resolución de cuadernillos que contenían preguntas semejantes a las que contiene la prueba. El interés era mejorar los puntajes y considerar éstos como evidencia de logro educativo y de mejora de la calidad de la educación. Ésta si se puede considerar una modificación en la práctica docente significativa

\section{La evaluación de los docentes.}

Ante la significativa pérdida del poder adquisitivo del salario de los docentes en los años noventa, al inicio del establecimiento de las políticas neoliberales centradas en la calidad, evaluación y eficiencia. En particular en atención a una recomendación reiterada del Banco Mundial y de la CEPAL-UNESCO, y posteriormente a la OCDE; la autoridad educativa, estableció en acuerdo con el Sindicato de Maestros (SNTE) el Programa Carrera Magisterial (1993). Un programa inspirado en las propuestas desarrolladas en los EEUU de pago al mérito (merit pay), que de acuerdo con Cooke se iniciaron en aquel país desde 1908. (Colado, 1993) 
El programa Carrera Magisterial fue un programa de evaluación docente, de carácter voluntario durante un poco más de 20 años, el que permitía obtener un beneficio en la percepción económica de los docentes. A diferencia de otro tipo de evaluación profesional, que toma en cuenta la trayectoria de formación docente, este programa ponderó elementos que consideró cercanos a su desempeño. La formación previa tenía el puntaje más bajo en la ponderación del programa, mientras que el resultado que obtuvieran los alumnos en un examen a gran escala tenía una mejor puntuación llegando a ponderar hasta el $50 \%$ en la última etapa del programa. Inicialmente el examen de logros de aprendizaje sólo se aplicaba a aquellos grupos donde el profesor se hubiera inscrito para ser evaluado en el programa. Otro examen existente en el programa fue el primero que se aplicó a los docentes construido con base en conocimientos psicopedagógicos y del currículo su ponderación porcentual se mantuvo durante todo el programa. La última ponderación inicialmente era proporcionada por el director de la escuela. (Díaz Barriga, 1996)

El programa funcionó como un sistema de evaluación voluntaria que ofrecía una retribución económica al docente de acuerdo a los resultados obtenidos. Algunos estudios mostraron que no había evidencia significativa entre los resultados de aprendizaje de los alumnos cuyos docentes participaban en este programa y de los que no participaban (Santibañez, y otros, 2006).

Ante esta realidad, en 2011 este programa se transformó en uno de carácter obligatorio denominado Evaluación Universal de los Docentes, por el cual los docentes de manera gradual, esto es los que estaban en Carrera Magisterial cuando les correspondiera ser reevaluados y, los demás en función del lugar y grado que estuvieran atendiendo, tendrían que ser evaluados (resolver esos exámenes). A la obligatoriedad de participar en el mismo se mantuvo la visión de entregar un estímulo económico, en este caso la ponderación del resultado que obtuvieran los alumnos en la prueba ENLACE la contaría el $50 \%$ de la puntuación. Asignación que hizo que algunos docentes dedicaran más o menos tiempo para entrenar a sus estudiantes en la resolución de este tipo de exámenes. La impresión y uso de cuadernillos con preguntas y respuestas para trabajar con los alumnos intensificó su empleo en el aula, los docentes modificaban su práctica en el aula, no en el sentido esperado desde una perspectiva didáctica

El programa de Evaluación Universal sólo funcionó un año pues a finales de 2012, dado que nuevamente regresó el PRI a ocupar la Presidencia de la República. Una de las primeras acciones de ese gobierno fue lograr un Acuerdo Nacional con los principales partidos políticos de ese momento, para realizar cambios radicales en el marco del proyecto neoliberal. Si bien, el país estaba integrado a la OCDE desde 1994 y este organismo emitía estudios y recomendaciones específicas durante todo este tiempo, múltiples documentos en un año civil. Con el regreso del PRI al poder, la OCDE asumió un papel más relevante. Al grado que en ocasiones se expresaba que no era necesario tener un Secretario de Educación, si finalmente la OCDE operaba como un Súper-Ministerio Internacional que establecía lo que cada país tendría que realizar.

En menos de 15 días de haber asumido el poder, la Presidencia de la República envió un proyecto de reforma constitucional que mostraba que México asumía puntualmente las 
recomendaciones en materia educativa formuladas por la OCDE, en particular las derivadas del acuerdo 2010 (OCDE, 2010), en el que recomendaba establecer un sistema de evaluación docente con consecuencias, esto es, con despidos a los docentes que no obtuvieran los resultados esperados. La idea de alguna manera era imitar la experiencia chilena aunque con mayor signo autoritario.

Diciembre de 2012 y los primeros nueves meses de 2013 permitieron al gobierno entrante establecer una serie de cambios en la legislación constitucional y en las leyes secundarias de educación que establecieron la obligatoriedad para los docentes de ser evaluados periódicamente, los resultados obtenidos también tendrían diversas consecuencias, entre ellas se daría un estímulo económico a quiénes salieran destacados y al mismo tiempo perderían su empleo los que tras tres evaluaciones (resolución de exámenes) ${ }^{11}$ sus resultados fueran no satisfactorios. Aspecto que afectó las relaciones entre autoridad y docentes, porque incluso se contravenían historias personales donde se había obtenido estabilidad laboral en la plaza docente. El tema de la estabilidad es vigente en las leyes laborales del país, pero la reforma había logrado que constitucionalmente se hiciera una excepción para quiénes trabajan en la educación. No sería la única excepción que se llevaría a cabo con tal de cumplir las recomendaciones de la OOCDE.

De igual manera legislación educativa aprobada establecía que cualquier persona, egresada de la educación superior que obtuviera un puntaje satisfactorio en un concurso de oposición, traducido en las acciones a un examen de conocimientos pedagógicos y curriculares, obtendría una plaza docente temporal. Con esta modificación cualquier egresado de educación superior podría ser docente en algún nivel del sistema educativo, desde preescolar hasta enseñanza media superior. De facto se desconocía la tarea que realizaban las instituciones de formación inicial de docentes, tema que obviamente molestó a los docentes. ${ }^{12}$

Ambos elementos en realidad constituyeron una descalificación profesional, tema que causó gran molestia en el sector docentes. Unos la expresaron básicamente en las redes sociales, otros en manifestaciones esporádicas, donde se distinguió una marcha de protesta docente que iniciaba con una manta que expresaba "Evaluación sí, pero no así" y, un grupo más activo tuvo una permanente confrontación pública solicitando la derogación de la ley. ${ }^{13}$

Las escuelas de formación inicial de docentes, comenzaron a reorientar el trabajo con sus alumnos, sin necesidad de un cambio curricular, con la finalidad de prepararlos para los cinco elementos que calificaba el examen nacional de ingreso (en la ley concurso de oposición).

Al mismo tiempo se confirió al Instituto Nacional de Evaluación Educativa (INEE) la responsabilidad de supervisar todo el proceso de evaluación del desempeño docente. Entre tres instituciones dos gubernamentales y una autónoma se distribuían las tareas y la aprobación de las mismas. Finalmente, en público era el INEE el que aparecía como responsable de esta tarea, cuestión que sería determinante para que la institución fuera cancelada en 2019.

En 2015 se realizó la primera evaluación obligatoria del desempeño docente. A pesar de las protestas abiertas de un grupo de docentes integrados a la Coordinadora Nacional de 
Trabajadores de la Educación, cuya mayor presencia se encuentra en los estados de mayor pobreza económica en el país (Guerrero, Oaxaca y Chiapas), se seleccionó, de manera un tanto arbitraria, a los docentes de preescolar, primaria, secundaria y bachillerato que les correspondía presentarse a la evaluación.

Los medios de notificación a cada docente fueron muy variados. En algunos casos fue el director de la escuela, en otros un oficio que se hizo llegar al docente. Ningún elemento fue vital fue considerado para ser excluido una vez que había sido elegido por este sistema para ser evaluado. La consecuencia por no presentarse a la evaluación fue el despido inmediato, por no cumplir una norma constitucional. Ningún docente pudo alegar una situación personal, como una enfermedad o incluso la conclusión de un embarazo, (DiazBarriga A. , 2016) ${ }^{14}$ todos los que fueron seleccionados, unos al azar, otros en función de su cercanía o lejanía con su autoridad inmediata, tuvieron que presentarse el día y en el lugar designado.

Las tareas previas a la evaluación llevaron a muchos docentes a descuidar sus clases, no tenían tiempo para prepararlas, ponían a los alumnos a resolver ejercicios mientras ellos intentaban reunir las evidencias solicitadas en la evaluación, prepararse para resolver el examen en función de la bibliografía que establecía como guía para la evaluación; juntar las evidencias solicitadas no fue tarea fácil, los docentes tenían que entrar a una página específica de internet donde con su clave personal tenían que subir la información, no sólo tuvieron que adquirir o mejorar su equipo de cómputo personal, buscar lugares donde hubiera conectividad, sino también elegir y clasificar evidencias. Los cuadernos de los tres mejores alumnos y de los tres más deficientes; en otro momento fotografías de las actividades que realizaban con los alumnos, pero de acuerdo a la ley de protección de datos personales, los rostros de los alumnos no se podían identificar. Docentes que repetían una o dos veces la misma secuencia didáctica con los alumnos para poder juntar las evidencias e incluso un docente que, en entrevista relató que pagó a sus alumnos para que asistieran a una sesión extra, con la finalidad de obtener las evidencias de su trabajo a través de fotografías.

Lo importante no fue mejorar el trabajo docente, sino obtener y subir las evidencias, además todo ello tenía que ser en el tiempo establecido. El sistema se abría un día a determinada hora y se cerraba en otro día a determinada hora. De la misma manera tenían preparar un examen con base en la bibliografía que establecía una guía específica, la que no necesariamente respondía a la que trabajaba y conocía el docente. La angustia ante la evaluación era por demás mayúscula y evidente, desde obtener una calificación no aprobatoria o baja en la evaluación, hasta la imagen que eso generaría entre sus compañeros de trabajo y entre los padres de familia de su escuela. Quizá la única parte positiva que se podría considerar de esta experiencia fue que varios docentes crearon grupos de estudios entre ellos. Pero tampoco se puede desconocer la expresión de varios docentes de que durante seis meses descuidaron a sus alumnos para atender y procurar las exigencias que el sistema de evaluación impuso.

El día de la evaluación fue un momento altamente complicado, se reconoció que se había militarizado la evaluación, incluso se consideró que ésta era la aportación mexicana a la realización de esta actividad. (Diaz-Barriga A. , 2016) Los lugares donde se convocó para 
presentarse al examen que sería realizado a través de un sistema digital, estuvieron acordonados por policías federales e incluso en algunos lugares por militares.

El docente convocado a ser evaluado sólo se le permitía ingresar con su identificación personal, dejando todas sus cosas afuera. Sus compañeros ubicados en los alrededores de este sitio le gritaban cosas ofensivas, entre otras traidor. Una vez que se revisaba su identificación, asegurándose que estaba en la lista de convocados, dos policías lo conducían a un segundo lugar, algunos docentes lo llamaron "retén" donde nuevamente era revisado que estuviera en la lista y, entonces le asignaban el aula a la que debía presentarse, un policía lo acompañaba hasta la puerta de la misma. Un docente describió esta situación como el trato a un prisionero.

La experiencia de 2015, sin duda fue traumática para quiénes lo vivieron. La evaluación realizada a través de una computadora donde se establecían los tiempos para cada actividad duró ocho horas. Un docente describió que durante esas horas, ni siquiera se movía para satisfacer sus necesidades fisiológicas, pues no quería perder tiempo en la resolución de lo que establecía la computadora.

Para vigilar a los docentes en cada aula se contrató a un egresado de licenciatura a quien se capacitó en temas tecnológicos, por si un equipo tenía dificultades de funcionamiento. Eso fue todo menos una evaluación del desempeño.

Los responsables del INEE reconocieron algunos aspectos como errores que serían mejorados para la convocatoria de 2017. Ante el cuestionamiento de como asignaban los puntajees explicaron la diferencia en establecer puntuaciones en instrumentos de respuesta cerrada y en instrumentos de respuesta construida (las evidencias entregadas). Pero en todos se aplicaba un modelo estadístico sólo que los primeros los exámenes eran calificados directamente por la computadora, mientras que las evidencias (planeaciones, cuadernos de los alumnos en pdf, fotografías del trabajo en grupo) eran primero procesados en forma personal por profesores capacitados a través de una rúbrica, que contenía cinco indicadores. La valoración cualitativa de la rúbrica, al colocarse en el sistema de cómputo diseñado inmediatamente asignaba un puntaje numérico. Con la unión de ambos puntajes se generaba el puntaje obtenido por el docente el que se traducía en los valores: Insuficiente, suficiente, bueno o destacado. Varios docentes a los que les faltó un punto en la escala primera de 1600 y modificada a 170 puntos sin ninguna explicación previa. Los docentes se preguntaban que les faltó cuando el punto de corte entre una calificación y otra era sólo de un punto (999 en vez de 1000, en la primera por ejemplo), para en vez de insatisfactorio obtener satisfactorio. La medición educativa y la psicometría fueron la base de esto que se denominó evaluación del desempeño docente, tema que se publicó en un documento oficial del gobierno mexicano, cuando es expresamente un documento específico de expertos de medición. (INEE, 2018)

Los resultados se publicaron clasificando a los docentes en cuatro tipos de desempeño: Insuficiente, Suficiente, Buenos y Destacado, a los docentes que obtuvieron el resultado de destacado se les concedió por cuatro años un sobresueldo del 35\%, a cambio de renunciar a la estabilidad en el empleo que habían obtenido años antes.

El INEE intentó mejorar la forma en como realizaba esta experiencia, mejorar el tipo de evidencias que solicitaba, pero no logró que la actividad realizada fuera una evaluación del 
desempeño, simple y llanamente se convirtió en un ejercicio de medición y clasificación de docentes.

Esto explica la demanda de los docentes para cancelar la evaluación y cancelar la ley, demanda que con la llegada de un nuevo gobierno, el primero abiertamente de izquierda, en realidad nacionalista, cumplió con esta demanda modificando la Constitución al cancelar la obligatoriedad de la evaluación y con ello también desapareció al INEE en 2018. Tema que será objeto de futuras polémicas.

Hemos mostrado algún esbozo de la manera como la injerencia de los organismos internacionales ha logrado algunas modificaciones en la práctica docente. Si bien, queda claro que las mismas son resultado explícito de un conjunto de políticas de calidad y eficiencia que se iniciaron como políticas curriculares, pero que fueron acompañadas por políticas de evaluación logrando un impacto en el trabajo docente.

c) La formación inicial de docentes en las escuelas normales

El cambio más fuerte que sufrieron las escuelas de formación inicial de docentes su plan de estudios se realizó en 1984, cuando los planes se equipararon con los estudios universitarios. Para ello se exigió que para ingresar a la escuela normal los aspirantes hubiesen concluido los seis años de enseñanza media y no los tres primeros años, como se realizaba previamente.

El plan de estudios de 1984 fue inspirado en lo que realizaban las universidades en materia de los programas de licenciatura en educación, con la diferencia de que en las escuelas normales se seguía conservando la práctica docente desde el primer año de estudios.

La segunda reforma curricular se va a realizar hasta 1997, tres o cuatro años después de que se estableciera la reforma constructivista en la educación básica y se retornara a planes de estudios por asignaturas y no por áreas de conocimiento. Este plan de estudios construido bajo la consigna de "abajo el teoricismo" eliminó de las materias de formación docente todas aquellas que consideraron teóricas: filosofía de la educación e historia de la educación, pero también eliminaron las pedagógicas, por ejemplo didáctica fue reemplazada por planeación de la enseñanza, psicología del aprendizaje y psicología infantil o de la adolescencia fueron eliminadas. En su lugar se estableció lengua materna y su enseñanza, matemáticas y su enseñanza, etc. En la suposición de que el docente de lengua, matemática o historia podría al mismo tiempo trabajar los retos pedagógicos de su enseñanza. Se supuso ingenuamente que la transposición didáctica se daría de manera automática (Chevallard, 1991), que el docente de una asignatura era capaz al mismo tiempo de trabajar los conocimientos de dicha asignatura y las formas didácticas para su enseñanza. En la realidad privó lo primero, mientras que lo segundo fue desapareciendo. Por primera vez, en la historia de la educación materias sustantivas en la formación inicial de los docentes quedaron suprimidas.

Se partió de la idea, no necesariamente lograda, de que los docentes del grupo escolar donde los estudiantes realizaban su práctica se convertirían en tutores de los alumnos. No había ningún criterio para seleccionar a estos docentes, algunos cumplieron con esta función, la mayoría en realidad consideró que la presencia de un estudiante de normal, responsable de preparar y dar las clases que establece el plan de estudios, los liberaba de esa responsabilidad. 
Los docentes de la normal que orientaban el trabajo de los alumnos en el último año cuando tenían que realizar la práctica intensa, enfrentaban el problema de que esos estudiantes no se habían formado en la literatura pedagógico-didáctica mínima que le diera sostén a su trabajo

De igual manera resulta interesante observar la manera como en la política curricular hacia la formación inicial de docentes se postergan los cambios de en los planes de estudios, pues primero se realizan las modificaciones en la educación básica y años después de adecúan esas los que corresponden a la educación normal. Estos planes al igual que los de la educación básica tienen un carácter nacional, más allá de la lucha que en el año 2018 realizaron los docentes para que se concediera autonomía curricular a las escuelas normales, esta aspiración aún no se logra.

Sin embargo, las normales siguen teniendo su contacto con la escuela de educación básica que les corresponde (preescolar, primaria y secundaria), ya que desde el primer año los estudiantes están realizando observaciones en las aulas de esas escuelas y, a partir del segundo año empiezan a realizar una práctica docente graduada, la cual es intensa en el último semestre de su formación.

Algo que es importante destacar es que el intento que el neoliberalismo ha tenido para lograr un cambio en la forma de pensar y trabajar de los docentes que establecían las políticas educativas, enfrentaron a una lógica que forma del ADN de las escuelas normales. Pues estas escuelas más allá de los cambios curriculares, mantuvieron como si fuera la sangre de sus venas $\mathrm{y}$, no necesariamente de manera consciente, el ideario de formar un maestro humanista que entendiera las necesidades de la sociedad mexicana, que no olvidara los principios educativos que se derivaban del nacionalismo que surgió a partir de la revolución mexicana de principios del siglo XX (Diaz-Barriga, 2021), esta situación formó una generación de docentes que podríamos calificar como híbrida, pues si, por un lado tenían en mente la atención a los logros de aprendizaje y a su participación en el programa de evaluación Carrera Magisterial, por la otra, reproducían y la misma escuela pública reproducía una serie de valores nacionalistas que están presentes en el actuar de los maestros.

d) La creación de proyectos curriculares desde la cosmovisión indígena

El levantamiento indígena de los zapatistas en 1994 ha logrado impactar en la práctica docente que se realiza en instituciones educativas de estas zonas. Inicialmente los zapatistas establecieron de manera simbólica lo que denominaron comunidades indígenas autónomas, esto es comunidades que se rigen por sus usos y costumbres. Lo que también significó construir de manera lenta, pero importante un proyecto educativo acorde a las condiciones y demandas de estos grupos. (Baronnet, 2015).

Tardíamente, pero con un trabajo tenaz se comenzará a ver y reconocer hasta la segunda década del siglo XXI, a partir de la divulgación de algunos documentos y textos que permitan dar cuenta de un proyecto de educación popular, con clara atención a los grupos originarios, indígenas en su expresión, (Angeles, 2017) que se alguna forma de sale del molde que habría impuesto por la lógica de eficacia de los Organismos Internacionales. Al establecer proyectos específicos como el PETEO (Propuesta Educativa de Transformación para el Estado de 
Oaxaca) o el PDEDCEM (Programa Democrático para la Educación y Cultura para el Estado de Michoacán).

De esta manera, mientras en los planes curriculares oficiales y en las políticas de inducción del trabajo docente se profundizó en el conjunto de acciones en pro de la calidad de la educación, en su expresión curricular y en los sistemas de evaluación docente vinculados a recompensas salariales; los movimientos cercanos a los indígenas y a los grupos sociales más vulnerables, reaccionaron de manera lenta y sin necesariamente contar con un elemento articulador entre ellos, construyendo respuestas específicas adecuadas al contexto donde laboraron. Estas respuestas siempre quedaron en un plan marginal, lo que no significa que no tuvieran su fundamentación tanto en la cosmovisión indígena de cada pueblo originario, como en la lectura de diversos autores de la pedagogía como Freinet, Freire, Makarenko, e incluso del movimiento denominado pedagogía crítica, sobresaliendo probablemente los trabajos de Peter McClaren y Henri Giroux. Proyectos marginales que alcanzaran su expresión más estructural hasta el siglo XXI. Pero proyectos que constituyen una significativa aportación práctica y conceptual a la educación popular. Proyectos curriculares en las que los docentes y alumnos modifican el rol que han asumido históricamente.

\section{Antes de concluir}

Cansada la mayor parte de la sociedad de la corrupción, del enriquecimiento inexplicable de los políticos la elección de 2018 determinó de alguna forma el fin de período neoliberal en el país. Eso no significa que todas las instituciones y varias de las prácticas sociales establecidas por el mismo se hayan suprimido. El nuevo gobierno cumplió la promesa de eliminar la obligatoriedad de la evaluación, modificó la Constitución y las leyes secundarias, pero no ha logrado armar un proyecto educativo que tenga la coherencia esperada, tema que tendría que ser objeto de otro análisis. Entre sus propuestas pedagógicas esta la construcción de la nueva escuela mexicana, un discurso hasta este momento todavía no ha logrado presentarse en una forma consistente en el plano pedagógico. Quizá lo único que se pueda afirmar en este momento es que busca enfatizar en la necesidad de fomar ciudadanos que vean a su comunidad y no a su individualidad. Tema que reclama una construcción más sólida que pueda ser la guía de una política curricular diferente. En la actualidad se vive una mezcla planes de estudios que dejó la reforma de 2011 y de 2017. El futuro educativo del país aún no está totalmente definido, aunque debemos reconocer que la pandemia de 2019 vino a suspender muchas de las acciones que se estaban desarrollando en ese sentido.

\section{Conclusiones}

Reconocemos que los años de los gobiernos neoliberales gestaron una política curricular y de evaluación que tuvo impacto en el sistema educativo, se logró modificar varios 
elementos de la práctica docente, pero no ésta en su conjunto. Al mismo tiempo no necesariamente las prácticas que se generaron son exactamente las que se buscaban.

En estricto sentido no podemos afirmar que a partir de este momento se hayan modificado sustancialmente las formas de realizar la docencia en el aula, pero de alguna forma entre la reforma de los años setenta del siglo pasado que incluyó el diseño curricular por objetivos de aprendizaje y la implantación, ya en el marco de las políticas educativas de corte neoliberal en los años noventa de ese siglo se establecieron las señales para modificar la visión de los docentes sobre su trabajo en el aula.

En este entramado de procesos tanto a nivel global en el discurso inicial de los organismos internacionales, como a nivel local, se partió de descalificar a los docentes y buscar hacer de lado el discurso pedagógico y la investigación educativa, en particular la de corte didáctico centrada en el tema formación de las potencialidades y capacidades del ser humano. Este planteamiento fue reemplazado por un discurso donde se fortaleció la idea tecnocrática de formación del capital humano apoyado en un momento por el constructivismo y en otro por el enfoque de competencias.

De esta manera, generaron dos tipos de comunidades de educación, aquellas orientadas a una perspectiva tecnocrática del trabajo educativo y, las que desde una perspectiva cercana a la pedagogía de corte humanista buscaron orientar el trabajo docente. De alguna forma se podría afirmar que se iniciaba un amplio debate entre grupos que se adecuarían a las doctrinas de corte eficientista y asumían el reto de la calidad de la educación, frente a grupos que defendían una perspectiva didáctica en el trabajo en las aulas. Apoyados estos últimos en muy diversos cortes conceptuales, desde las posiciones freirianas de los años setenta, los planteamientos del movimiento de didáctica y educación argentino que la migración, tras los golpes militares en esa nación, posibilitó en un grupo de académicos mexicanos, hasta las perspectivas de análisis institucional provenientes de Europa que tuvieron una importante influencia en esos años. No se puede afirmar que hubiese existido una coherencia o articulación entre estos distintos planteamientos, sencillamente habría que reconocer que fue un discurso de búsqueda y construcción de alternativas ante condiciones sociales diversas. También será necesario reconocer que este discurso fue marginado paulatinamente hasta mostrar la cara más tecnocrática a partir de la década de los años noventa, década donde los proyectos económicos neoliberales, tuvieron un impacto significativo en la política educativa.

El desencanto de la sociedad no necesariamente ante los temas educativos, sino ante la corrupción y enriquecimiento de la clase política permitió que, por primera vez, en 2018 llegara un grupo al poder de corte nacionalista con rasgos de izquierda, pero este grupo no ha logrado establecer más que medidas políticas en educación amplia, como gratuidad en la educación superior ( $\sin$ lograr que necesariamente se cumpla) mientras que los proyectos más de índole pedagógica no se han generado.

Por otra parte, se reconoce que desde los movimientos indígenas, desde sus comunidades se están gestando prácticas pedagógicas diferentes que si bien se apoyan en autores del siglo $\mathrm{XX}$, como Freire y varios de la pedagogía crítica, al mismo tiempo se pueden considerar 
como una aportación mexicana a la reflexión y práctica docente en contextos de diversidad social.

\section{Notas:}

1. Al respecto vale la pena considerar que Cremin, al revisar las actas de la NEA (National Educational Asociation) de los EEUU, reconoció que mientras las actas de 1890 hacian referencia a la necesidad de la formación de la mente, valores y formas de actuar de los educandos, por el contrario las de 1920 ya se referían a los logros que las escuelas tenían que ofrecer a partir del trabajo con los estudiantes. El autor concluye que el pensamiento eficientista ya formaba parte de la nueva generación de educadores. (Cremin, 1962).

2. Encontrar un documento de los Organismos Internacionales a principios de los años noventa era una tarea titánica. En la ciudad de México existía una oficina donde en los primeros 5 años de la década se podían adquirir los documentos impresos, pero no había difusión sobre el sitio donde se encontraba la oficina, en realidad la pude localizar gracias a que pude en un viaje a Buenos Aires, una profesora de posgrado me indicó donde se encontraba la oficina de esa ciudad, obviamente en un lugar también desconocido. Fueron ellos los que me dieron razón de la oficina en México. Conforme se fue ampliando la información digital en internet. Todos los organismos Banco Mundial, Banco Interamericano de Desarrollo, UNESCO en sus diferentes oficinas y la OCDE han facilitado el acceso a esa información en la red. Textos a los que en este momento se puede tener acceso prácticamente abierto.

3. Un diagnóstico que exhibía las deficiencias del sistema y que consideraba que el docente era fundamentalmente la razón de ellas, en ningún momento analizó la diversidad del sistema, el impacto que causó la expansión geométrica del sistema educativo nacional, en particular la educación primaria en donde se obtuvo prácticamente la cobertura nacional, la diversidad de los grupos sociales que recientemente tenían acceso al sistema, las condiciones socio económicas y culturales de sus grupos familiares; la dificultad de la política educativa para ofrecer respuestas satisfactorias a todos e incluso la dificultad para incrementar las instituciones de formación inicial de docentes. Se abandonó un tanto a las instituciones centenarias, así como a las dedicadas a la formación para el sector rural y se expandieron sin mucho cuidado las escuelas normales en el país.

4. Modernización es un tema del que se abusa cuando se establecen políticas educativas. A fines de los años cincuenta con el establecimiento del plan de estudios para la educación primaria por áreas de conocimiento se conformó una incipiente modernización una visión social de esta modernización fue el establecimiento del libro de texto gratuito, tema pionero en América Latina, junto con el programa de desayuno escolar; una segunda modernización educativa se establece a través de la reforma curricular de 1972, donde ya se incorporó la visión tecnicista del currículo de corte estadounidense y la teoría de objetivos, pero conservando el debate didáctico nacional, el libro Didáctica y curriculum (Díaz-Barriga, 2004), es un claro ejemplo de ello. La modernización educativa gestada en los años noventa, ya ampliamente de corte neoliberal será la tercera de la segunda mitad del siglo XX.

5. Taba 1974 establece que analizar los planes de estudios por asignaturas es como si se realizará una expedición arqueológica en donde se pueden encontrar huellas de muchos años previos en los proyectos curriculares.

6. Muy significativo resulta recordar que los últimos textos de ciencias sociales integraban los eventos del descubrimiento de América, o la conquista de diversos países de la región, al contexto que en ese momento 
se vivía en Europa. Invasiones de franceses entre otros no sólo eran vistas como un evento local que afectaba a un país, sino en el entorno internacional donde esto se estaba dando. Al regresar a los cursos de historia se estableció el de historia patria, historia de América Latina e historia universal. Todo desligado completamente.

7. Este tema no es raro, Tardif muestra como desde inicios del siglo XX la psicología, en particular la psicología del aprendizaje va desplazando el campo de la didáctica (Tardif, 2010).

8. Algunas investigaciones realizadas como la Tesis de Maestría de Silvia Martínez sobre la Enseñanza de la Lecto Escritura en Primero de Primaria mostró como un docente decidió emplear el método onomatopéyico de los años cincuenta del siglo pasado, para trabajar con sus alumnos argumentando que era más eficiente que el propuesto en los programas de estudio. Martínez, (2016)

9. Hubo una fiebre sin sentido para la enseñanza del inglés, incluso cuando el Gobierno del Presidente Trump empezó a expulsar a algunos de los "dreamers" estudiantes de origen mexicano se consideró que estos podrían ser contratados como maestros de inglés en todo el sistema educativo. Recordemos que este programa Daca (Programa de Acción Diferida para los Llegados en la Infancia), fue creado por el presidente Obama para proteger a los que no tenían papeles legales pues sus padres los trasladaron siendo niños, pero que toda su educación, hasta la superior la realizaron en Estados Unidos. Los pocos que llegaron a México dejaron claro que no tenían la aspiración de ser contratados como docentes.

10. Un debate puntual se da este año 2021 a raíz de la declaración del Presidente de la República de que México participará en la próxima edición de la prueba PISA, la sociedad de se expresa dividida unos plantean que hay que seguir conociendo lo que los alumnos obtienen, mientras que otros sostienen que el significativo costo de participar en PISA no justifica el aceptar la aplicación de la prueba, dado que ese dinero es mejor que se invierta en la infraestructura escolar. Cerca del $40 \%$ de las escuelas públicas carece de agua potable y/o de luz eléctrica. Al mismo tiempo se confronta a un gobierno que lucha contra el neoliberalismo y al mismo tiempo, protege a una institución insignia del neoliberalismo como lo es la OCDE.

11. La ley emplea el término evaluación, pero en realidad lo que se hizo fue aplicar exámenes a los docentes y solicitar evidencias de su trabajo en grupo que aunque eran valoradas de manera cualitativa en una rúbrica el sistema de cómputo inmediatamente asignaba un puntaje a las mismas.

12. En realidad el neoliberalismo buscó permanentemente disminuir o cerrar las escuelas normales. En parte, por el activismo social de las normales rurales, vinculadas con los sectores más desposeídos de la sociedad $\mathrm{y}$, por otra parte, impidiendo el desarrollo académico de estas instituciones.

13. Es necesario reconocer que gracias al activismo de la CNTE, con sus aciertos y errores, se crearon los elementos para cancelar la ley en 2019.

14. Entre los testimonios recabados a los docentes que presentaron esta evaluación se encuentra el de una profesora que tuvo una cirugía para extraer a su bebé (cesárea) y se presentó a los 8 días de que ésta de realizó, decía en la entrevista "sabía que no iba a aprobar, sólo realicé parte de las tareas, pero lo importante era que no me despidieran", mientras otro docente afirmaba "pregunté a abogados si podía ampararme me respondieron que no, pregunté a mis autoridades que podría hacer y me dijeron sólo que te mueras". Reunimos muchas evidencias sobre la indignación con la que los docentes vivieron este proceso.

\section{Referências}

Carnoy, M. (2000). La educación como imperialismo cultural. México: Siglo XXI.

Cedilo-Cedillo, A. (jul/dic de 2012). Análisis de la fundación del EZLN en Chiapas desde la perspectiva de la 
acción colectiva insurgente. (C. d. Chiapas, Ed.) LiminaR. Estudios sociales y humanidades, 10(2). Recuperado el 12 de 07 de 2021, de http://www.scielo.org.mx/scielo.php?script=sci_arttext\&pid=S166580272012000200002

CEPAL. (1992). Educación y conocimiento Eje de la transformación productiva. Recuperado el 08 de 2021 , de https://repositorio.cepal.org/bitstream/handle/11362/2130/1/S9250755_es.pdf

Cepal. (22 de Agosto de 2019). Modelos de estado desarrollista. Recuperado el 08 de 2021, de Revista Cepal no 28, p 39-52: https://repositorio.cepal.org/bitstream/handle/11362/44736/1/RVE128_Bresser.pdf

Chevallard, Y. (1991). La transposición didáctica: del saber sabio al saber enseñado. Buenos Aires: Aique.

Coraggio, J. L. (1995). Seminario "O Banco Mundial e as Politicas de Educação no Brasil”, organizado por Açao Educativa,. Las propuestas del Banco Mundial para la educación: ¿Sentido oculto o problemas de concepción. Sao Paulo: [https://coraggioeconomia.org] .

Cremin, L. (1962). La transformación de la escuela. Buenos Aires: Omeba.1990-1994, P. N. (1990). Recuperado el 08 de 2021, de http://dof.gob.mx/nota_detalle.php?codigo $=4642789 \&$ fecha $=29 / 01 / 1990$

Angeles, I. (2017). Pedagogía de la comunalidad. Herencia y práctica social del pueblo Iñ Barkuu. Cacahuatepec, Oaxaca: Escuela Normal Experimental Presidente Venuestiano Carranza.

BancoMundial. (1995). La enseñanza superior. Lecciones derivadas de la experiencia. Recuperado el 08 de 2021, https://documents1.worldbank.org/curated/en/274211468321262162/pdf/133500PAPER0Sp1 rior0Box215 0A1995001.pdf

BancoMundia. (1992). Educación Primaria. Documento de Política. Washington: Banco Mundial.

Baronnet, B. (jul/sept de 2015). La educación zapatista como base de la autonomía del sureste mexicano. Educacao \& Realidade, 40(3), 905-723.

Díaz Barriga, Á. (1996). Los académicos ante los programas Meryt Pay. En A. P. Díaz Barriga, Universitarios: Institucionalización académica y evaluación (págs. 9-121). Pensamiento Universitario, 86, Centro de Estudios sobre la Universidad. UNAM.

Diaz-Barriga, Á. (2021). Política de la educación Normal en México. Entre el olvido y el reto de su transformación. Mexicana de Investigación Educativa, 533-560.

Díaz-Barriga, A. (2004). Didáctica y curriculum. Convergencia en los programas de estudios. México: Paidós.

Diaz-Barriga, A. (2016). Una perspectiva pedagógico-social de los entramados que se han creado a partir de la evaluación del desempeño docente. En Mart, S. inez DELLA Roca, M. Aguirre, \& H. Radetich, Notas sobre la nueva reforma educativa (págs. 215 - 259). México: MAPorrúa.

Guevara, G. (. (1992). La catástrofe silenciosa. Fondo de Cultura Económica.

Hodara, J. (2014). Latinoamerica ante la Alianza para el progreso. En J. Hodara, Obras escogidas de Víctor Uriquidi (Vol. 5, págs. 329-346). México: El Colegio de México.

INEE. (2018). Diario oficial de la Federación. Recuperado el 08 de 2018, de Criterios técnicos y de procedimientos para el análisis de los instrumentos de evaluación, el proceso de calificación y las listas de prelación de los concursos de oposición para el ingreso al Servicio Profesional Docente en Educación Básica y Educación M: http://www.dof.gob.mx/nota_detalle_popup.php?codigo=5556440

Melendres, M. (2002). El Banco Mundial y las reformas educativas para la educación primaria en Colombia y México (1990-2000). México: Tesis para obtener el grado de Maestría Facultad Latinoamericana de Ciencias sociales [https://www.iisue.unam.mx/publicaciones/libros/calidad-educativahistoria-de-una-politica-para-la-desigualdad].

Nexos, L. d. (18 de 11 de 2018). Nexos. Recuperado el 23 de 2021, de https://cultura.nexos.com.mx/lasdecadas-de-nexos/

$\begin{array}{lllll}\text { Normales, } & \text { E. } & \text { N. } & \text { (2019). } & \text { Obtenido }\end{array}$ 
http://gaceta.diputados.gob.mx/Gaceta/64/2019/nov/MejEscNormales.pdf

OCDE. (2010). Acuerdo de cooperación México-OCDE para mejorar la calidad de las escuelas mexicanas. Recuperado el 12 de 06 de 2021, de https://www.oecd.org/education/school/46216786.pdf

Plá, S. (2019). Calidad educativa. Historia de una política de desigualdad. México: IISUE-UNAM.

Riquelme, R. (27 de 08 de 2018). ¿Que es el Tratado de Liber Comercio de América del Norte. El economista. Recuperado el 5 de 08 de 2021, de https://www.eleconomista.com.mx/internacionales/Que-es-el-Tratadode-Libre-Comercio-de-America-del-Norte-20161123-0111.html

Rodríguez-Cristerna, J., \& Ruiz, G. (2021). Panorama histórico de las evaluaciones de logro académico, estandarizadas y a gran escala en México. Voces de la Educación, 6(11), 113-134. Recuperado el 24 de 08 de 2021, de https://www.revista.vocesdelaeducacion.com.mx/index.php/voces/article/view/348/238

Santibañez, L., Martínez, J.-F., Datar, A., MacEwan, P., Messan-Setodji, C., \& Basurto-Dávila, R. (2006). Haciendo camino. Análisis del sistema de evaluación y del impacto del pograma de estímulos docentes Carrera Magisterial en México. Santa Mónica, California: RAND Corporation. Recuperado el 12 de 07 de 2021, de https://www.rand.org/content/dam/rand/pubs/monographs/2007/RAND_MG471.1.sum.pdf

Secretaría-de-Educación-Pública. (19 de 08 de 2011). Acuerdo 592 para establecer la articulación de la educación básica. Recuperado el 12 de 08 de 2021, de Diario Oficial de la Federación: https://www.sep.gob.mx/work/models/sep1/Resource/9721849d-666e-48b7-8433-0eec1247f1ab/a592.pdf

SEP. (2017). Nuevo Modelo Educativo. Recuperado el 10 de 07 de 2021, de https://www.gob.mx/cms/uploads/attachment/file/207252/Modelo_Educativo_OK.pdf

Simone, D., \& Hersh, L. (2006). Las competencias clave para el bienestar personal, económico y social. Málaga: Ediciones Aljibe.

Taba, H. (1974). Elaboración del currículo. Buenos Aires: Troquel.

Tardif, M. (2010). Los saberes del docente y su desarrollo profesional. Madrid: Narcea.

\section{Correspondência}

Angel Díaz-Barriga: Dr. en Pedagogía. UNAM, México, Investigador Emérito del Instituto de Investigaciones sobre la Universidad y la Educación (IISUE-UNAM), líneas de investigación didáctica, curriculum y evaluación educativa (No sé si es suficiente o requieren algo más amplio.

E-mail: $\underline{\text { adbc49@gmail.com }}$

Orcid: https://orcid.org/0000-0003-3849-7190

Texto publicado em Currículo sem Fronteiras com autorização dos autores. 